\title{
REED ROOTFELT FOR CONSTRUCTED WETLANDS
}

\author{
Imants Plūme \\ Latvia University of Agriculture, Technical faculty, Cakstes bulv. 5 Jelgava \\ LV-3001, Latvia
}

\begin{abstract}
The resources of lakes' overgrowth biomass increases in result of eutrofication process in more than 2000 lakes in Latvia. Usage of lake reed rootfelt for filling of constructed wetlands can improve leachate treatment at a beginning period of operation and especially applicable in treatment plants with limited area. Physical and chemical properties of Reed rootfelt of lake Zebras were investigated to evaluate possibilities for rootfelt usage in constructed wetlands. The Reed rootfelt coalesces with the ground in coastal zone and is floating in the deeper areas of lake. Thickness of floating reed rootfelt layer varies from 0.25 to $0.8 \mathrm{~m}$. Density (without gravitational water) of reed rootfelt varies from $550 \mathrm{~kg} / \mathrm{m}^{3}$ at a surface to $1058 \mathrm{~kg} / \mathrm{m}^{3}$ in deeper layers if the rootfelt coalesces with ground. Investigated average density is $505 \mathrm{~kg} / \mathrm{m}^{3}$ and $814 \mathrm{~kg} / \mathrm{m}^{3}$ for floated overgrowth and rootfelt coalesced with ground respectively. The moisture content (without gravitational water, dry basis) of freshly removed floated rootfelt changes from $523 \%$ at a surface to $706 \%$ in deeper layer. If rootfelt was dried and moistened once more, moisture content remain practically same at a surface $(498 \%)$ and decreases 3 times in deeper layer (226\%). Investigated average organic matter content were $77 \%$ for floating rootfelt and $49 \%$ for rootfelt coalescing with ground. The specific energy of rootfelt cutting is $8,6 \mathrm{~kJ} / \mathrm{m}^{2}$ for oscillating saw, $18.1 \mathrm{~kJ} / \mathrm{m}^{2}$ for vertical blade and $10 \mathrm{~kJ} / \mathrm{m}^{2}$ for blade sloped in $45^{\circ}$. Acceptable technology for rootfelt removal includes partitioning of overgrowth in pieces and/or layers by manually operated or powered cutters and floating of pieces of rootfelt to coastal stockpile. Pre-treatment of rootfelt includes washing out of inorganic sediments, draining of the excess (gravitational) water and drying slightly only, to preserve growing ability of rootfelt. Thickness of rootfelt pieces can be increased for filling of area close to inlets in constructed wetlands to provide additional structure for enchanced flocculation and sedimentation. Methods of rootfelt pieces removal, handling and transportation avoid destruction of removed biomass and ensure high initial growing ability.
\end{abstract}

\section{KEYWORDS}

Constructed wetlands, lake rootfelt properties, overgrowth removal

\section{INTRODUCTION}

The wetlands for biological treatment have $1 . . .2$ years lasting start period, while seeded or planted reed biomass increases gradually. The usage of reed rootfelt pieces can provide high treatment ability for newly constructed wetlands. Rootfelt components - plant roots, plant litter and sediments provide solid surfaces for microbial activity important for converting of nitrogen and phosphorus into soluble forms available for plants. Much of reed stalks remains standing as dead biomass and provides additional structure for enchanced flocculation and 
sedimentation that is important in wetlands treatment performance throughout the annual cycle. Dead biomass, both standing and fallen, also is important to root viability under flooded, winter conditions because of the insulating layer it provides, in addition to its contribution to the internal load of the system [1]. Undecomposed litter from dead biomass provides storage for phosphorus, metals and other relatively conservative elements [2]. Reedfelt material due to flotation and high water absorbing abilities can maintain treatment capability of wetland during fluctuations or high peak inflows. Entire plant forms removed in lakes and filled into constructed wetlands ensure higher survival rate of plants compare to seeds or rootstock. The resources of lakes' overgrowth biomass increases due to increased usage of mineral fertilisers in agriculture and acceleration of eutrofication process in more than 2000 lakes in Latvia. Lake rootfelt removal is necessary activity during lakes' restoration process or before sediments (sapropel) extraction. Removed lakes' rootfelt is composed of common reed (phragmites australis) overgrowth in dominance. Investigation of reed rootfelt physical and chemical properties can contribute for development of suitable methods and technologies for rootfelt material removal, pre-treatment and utilisation in constructed wetlands.

\section{MATERIALS AND METHODS}

Help by visual observations and instrumental measurements general concept on rootfelt positioning in lake, its forming features, colour and other qualities were investigated. Instrumental observations include photographing or scanning of rootfelt samples. Help by instrumental methods was determined physical and chemical properties of rootfelt - specific energy for rootfelt partitioning, density, ash content, moisture and content of organic matter. Typical view of reed rootfelt is in Figure 1.

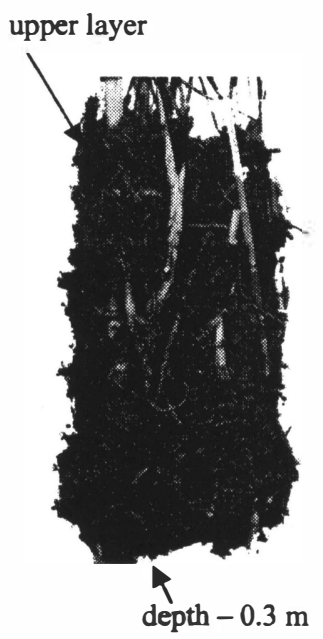

a)

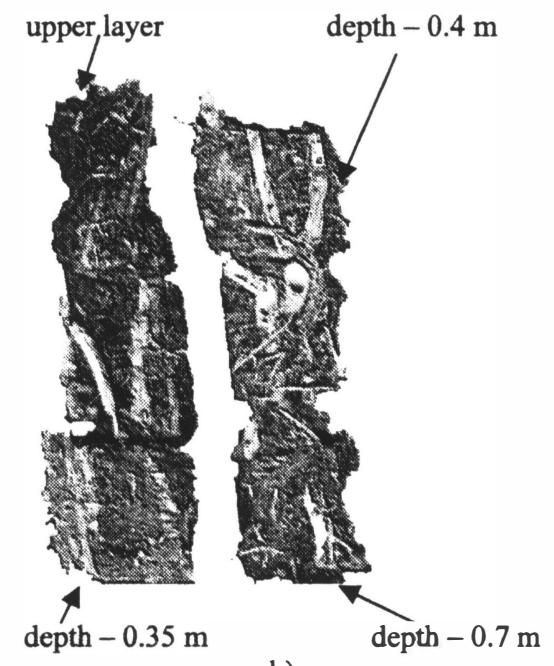

b)

Figure 1. Lake reed rootfelt; a) rootfelt layer in thickness of $0.3 \mathrm{~m}$ coalescing with ground, b) floating rootfelt layer in thickness of $0.7 \mathrm{~m}$. 
Special winch driven platform was used to investigate specific energy of rootfelt partitioning (Figure 2).

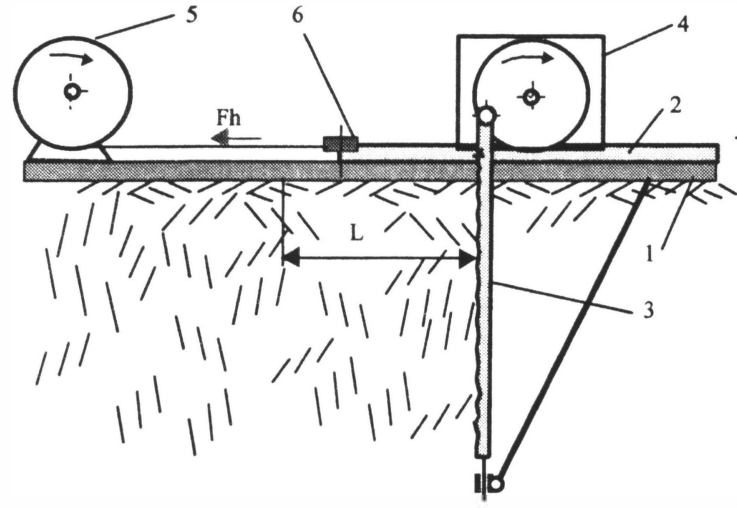

a)

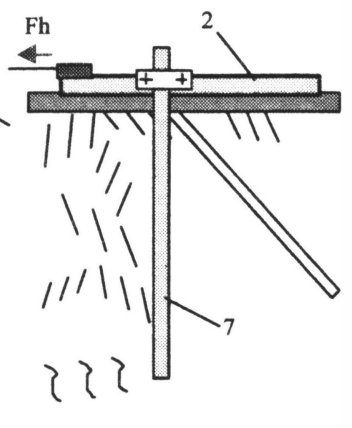

b)

Figure 2. Investigation of specific energy for rootfelt partitioning. a) Oscillating saw, b) Blade, 1-anchored platform, 2 - trolley, 3 -saw, 4-electric motor for saw oscillation, 5 -winch, 6-force sensor, 7-blade.

Blade or saw was used as a tool for partitioning of Reed rootfelt in field conditions. Electric motor was used to power oscillation of saw during its movement in horizontal direction. During similar experiment blade was positioned in rootfelt layer vertically or sloped in $45^{\circ}$. Specific energy for sawing or cutting of rootfelt were calculated:

$$
e_{p}=\frac{F_{h} L+N_{p} \theta}{s_{p}}
$$

where, $e_{p}$ - specific energy of partition on unit of area, N.m ${ }^{-2} ; F_{h}$ - force for tool transfer in horizontal direction, $\mathrm{N}$; $\mathrm{L}$ - tool transfer distance in horizontal direction, $\mathrm{m} ; \mathrm{N}_{\mathrm{p}}$ - power for saw oscillation, W; $\theta$ - transfer duration, $s ; S_{p}$ - disparted area, $\mathrm{m}^{2}$.

Help by measuring of volume and weight of biomass samples density of rootfelt was obtained. Samples were scaled at least 24 hours after rootfelt was extracted to drain the gravitational water.

The moisture (dry basis) of rootfelt samples was calculated:

$$
W=\frac{100\left(m_{0}-m_{s}\right)}{m_{s}}
$$

where, W - the moisture (dry basis), $\% ; m_{0}$ - initial weight of sample, $\mathrm{m}_{\mathrm{s}}$ - weight of dry matter of sample. 
Samples of biomass were dried at $105^{\circ} \mathrm{C}$ temperature during at least 8 hours for dry matter content investigation. Organic matter content for rootfelt sample was calculated:

$$
O_{v}=\frac{100 m_{p}}{m_{s}}
$$

where, $\mathrm{O}_{v}$ - organic matter content in sample, \%; $\mathrm{m}_{\mathrm{p}}$ - weight of ashes, $\mathrm{kg} ; \mathrm{m}_{\mathrm{s}}-$ weight of sample. Ashes were scaled after the samples were exposed at least one hour at $550{ }^{\circ} \mathrm{C}$ temperature.

\section{RESULTS AND DISCUSSION}

The reed overgrowth coalesces with the ground in a coastal zone and is floating in deeper areas in Lake Zebras. Width of coastal zone covered by reed overgrowth varies from $20 \mathrm{~m}$ to $90 \mathrm{~m}$. Thickness of floating reed rootfelt layer varies from $0.25 \mathrm{~m}$ to $0.8 \mathrm{~m}$. Floating rootfelt islands appears in lake sometimes after water level was heighten in a spring. The coalescing of some floating rootfelt islands with the ground is observed in dry summer periods while water level is low in watercourse.

The specific energy of disintegration of rootfelt varies in dependence on overgrowth partition method (Figure 3). An acceptable method for rootfelt removal can be the partitioning of overgrowth in pieces by manual operated or powered saw or by belt device [3] for overgrowth cutting in watercourses. Partitioned floating pieces can be delivered to coastal depository. For lowering of transportation expenses the rootfelt can be processed into strips. Method avoid mixing of removed rootfelt and is usable for production of reed roofelt material for filling in reed based constructed wetlands for sewage treatment. Pre-treatment of rootfelt includes draining of the excess (gravitational) water and drying slightly only, i.e. growing ability of rootfelt should be preserved.

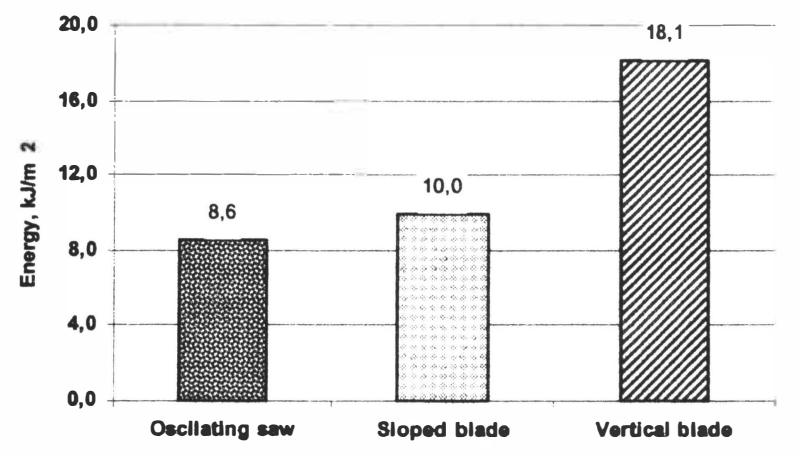

Figure 3. Specific energy of rootfelt cutting in dependence on overgrowth disintegration method

The thickness of pieces, strips and layers depends on method of filling of constructed wetlands. For example, thickness of rootfelt pieces can be increased for filling of area close to location of intake of polluted liquids in constructed wetlands as additional biomass provide enchanced flocculation and sedimentation of pollutants. 
Density of lake overgrowth was investigated both for coastal area, where rootfelt coalesces with the ground as well as for floated rootfelt positioned at a distance within $30 \ldots 80 \mathrm{~m}$ farfrom coast (Figure 4). Density of rootfelt coalesced with the ground varies from $520 \mathrm{~kg} / \mathrm{m}^{3}$ at

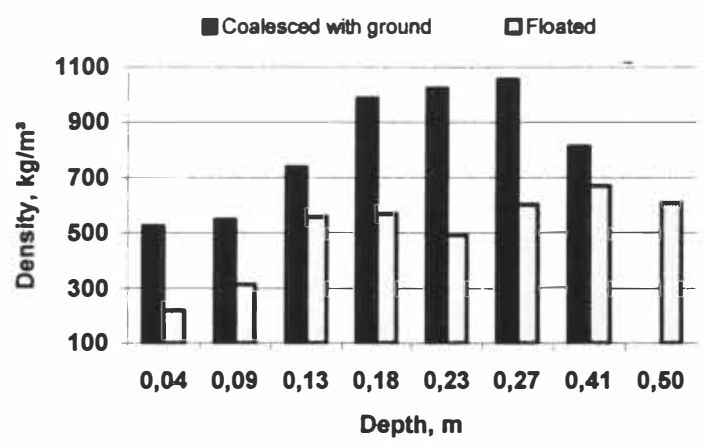

Figure 4. Density of lake overgrowth in dependence on depth of layer

a surface to $1050 \mathrm{~kg} / \mathrm{m}^{3}$ at a bottom, where reeds roots are coalesced in the ground. Density of floating rootfelt varies from $220 \mathrm{~kg} / \mathrm{m}^{3}$ at a surface to $670 \mathrm{~kg} / \mathrm{m}^{3}$ at a lower part of layer having depth of $0.4 \ldots 0.5 \mathrm{~m}$. Density is lowered beneath of floated layer where part of sediments is washed out by water. Investigated average density are $505 \mathrm{~kg} / \mathrm{m}^{3}$ and $814 \mathrm{~kg} / \mathrm{m}^{3}$ for floated overgrowth and rootfelt coalesced with ground respectively, therefore floated rootfelt is preferable for usage in constructed wetlands due to less transportation costs.

The moisture content of floating rootfelt varies in dependence on depth of samples and decreases after drying-moistening process, if the samples were dried down to $15 \%$ moisture and moistened again (Figure 5).

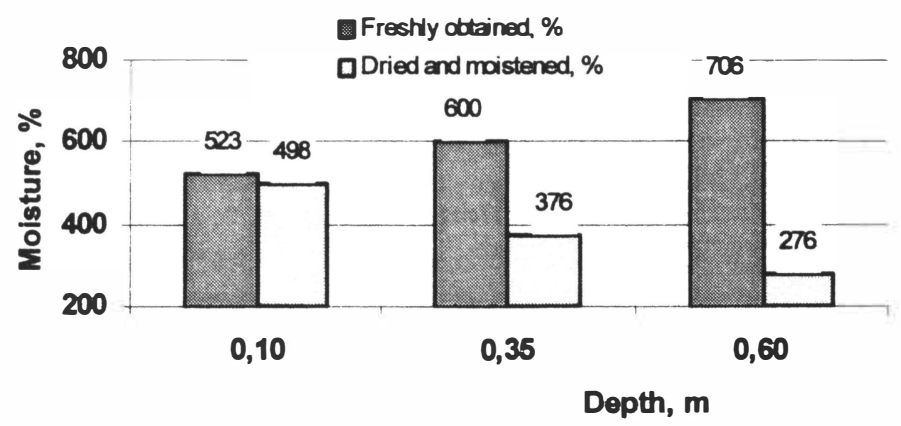

Figure 5. Moisture content (dry basis) for freshly extracted and for dried and moistened rootfelt in dependence on depth of samples. 
The rootfelt in lower part contain more sediments (sapropel) and therefore after drying partially lost absorbability.

Investigated organic matter content varies from $97 \%$ at upper part of floating rootfelt to $25 \%$ at lower part of rootfelt coalescing with the ground (Figure 6). Average organic matter content were $77 \%$ and $49 \%$ for floated rootfelt and for rootfelt coalescing with the ground respectively.

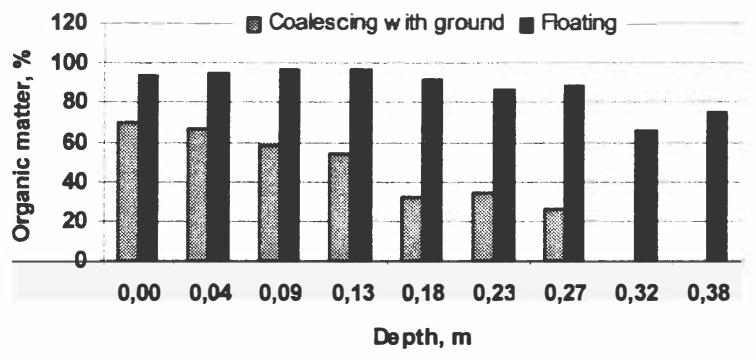

Figure 6. Organic matter content of reed rootfelt in dependence on layers' depth.

Dead organic matter of rootfelt are degraded in wetland gradually due to aerobic composting process in upper layer and anaerobic digestion process at a bottom. Standing dead biomass provides also structure for flocculation and sedimentation that is important in wetlands treatment performance throughout the annual cycle. The rootfelt layer has insulation properties and ensures treatment performance of wetland in winter conditions. The reed stalk material should be harvested annually to provide removal of plant nutrients. Rootfelt removal and wetlands filling can be performed during all seasons in a year, if the appropriate technology for rootfelt removal, pre-treatment, transportation and filling into constructed wetlands are used. Necessary condition is the preservation of growing ability of rootfelt during rootfelt handling, for example, special containers or pallets should be used for transportation of rootfelt from lake to wetland. The manually operated saw or powered cutters can be used for partitioning of lake rootfelt in layers, strips and pieces. Self-propelled or winch driven catamarans or special platforms equipped with powered cutters is recommended for large-scale reed rootfelt removal technologies. The floated rootfelt is more favourable for filling of constructed wetlands due to less weigh and higher content of organic matter, i.e. having less expenses for transportation and higher ability of degradation of pollutants in aerobic and anaerobic processes. Help by special pre-treatment technology inorganic substances can be washed out of rootfelt pieces, that resulted in increased organic matter content, reduced density and weight of rootfelt. 


\section{CONCLUSIONS}

1. The specific energy of rootfelt cutting is $8.6 \mathrm{~kJ} / \mathrm{m}^{2}$ for oscillating saw $18.1 \mathrm{~kJ} / \mathrm{m}^{2}$ for vertical blade and $10 \mathrm{~kJ} / \mathrm{m}^{2}$ for blade sloped in $45^{\circ}$.

2. Investigated average density is $505 \mathrm{~kg} / \mathrm{m}^{3}$ and $814 \mathrm{~kg} / \mathrm{m}^{3}$ for floated overgrowth and rootfelt coalescing with ground respectively.

3. The moisture content (without gravitation water, dry basis) of freshly removed floated rootfelt changes from $523 \%$ to $706 \%$ (dry bases) if layer's depth increases from $0.1 \mathrm{~m}$ to $0.6 \mathrm{~m}$. If rootfelt was dried and moistened once more, moisture content remains practically same at a surface and decreases 3 times in deeper layer.

4. Investigated average organic matter content were $77 \%$ for floated rootfelt and $49 \%$ for rootfelt coalesced with the ground. Investigated average organic matter content were $77 \%$ for floated rootfelt and $49 \%$ for rootfelt coalesced with the ground.

5. Investigated average density without gravitational water is $814 \mathrm{~kg} / \mathrm{m}^{3}$ are for floated rootfelt and $814 \mathrm{~kg} / \mathrm{m}^{3}$ for rootfelt coalesced with the ground.

6. The manually operated saw or powered cutters can be used for partitioning of lake rootfelt in layers, strips and pieces.

7. Self-propelled or winch driven catamarans or special platforms equipped with powered cutters is recommended for large-scale reed rootfelt removal technologies.

8. Floating rootfelt partitioned in strips, layers and pieces is favourable for constructed wetlands due to less density, less transportation expenses and handy filling into reedbeds.

\section{REFERENCES}

1. Manual. Constructed Wetlands Treatment of Municipal Wastewaters. Environment Agency, National Risk Management Research Laboratory, Office of Research and Development U.S. Environmental Protection Agency, Cincinati, Ohaio, 45268, September 2000, pp 154.

2. Kadlec, R.H and R.L. Knight. 1996. Constructed wetlands. Boca Raton, FL: Lewis Publishers, $893 \mathrm{pp}$.

3. Pat. LV-12155, SKI A 01 D 44/00. Device for overgrowth cutting in watercourses (Latvian)/ E. Kronbergs (LV), A. Kakitis (LV), I. Plume (LV). - Pieteikuma Nr. P-98119; Publ. 20. 02. 1999 // Patenti un Preč Zimes.-1999.-Nr. 2.-109. lpp. 